\title{
Conformity of Witnesses with Low Self-Esteem to Their Co-Witnesses
}

\author{
Tomoka Tainaka1, Tomoko Miyoshi' ${ }^{1}$, Kazuo Mori² \\ ${ }^{1}$ Department of Psychology, Kyoto Notre Dame University, Kyoto, Japan \\ ${ }^{2}$ Department of Educational Psychology, Tokyo University of Agriculture and Technology, Tokyo, Japan \\ Email: kaz-mori@cc.tuat.ac.jp
}

Received 17 August 2014; revised 12 September 2014; accepted 5 October 2014

Copyright (C) 2014 by authors and Scientific Research Publishing Inc.

This work is licensed under the Creative Commons Attribution International License (CC BY).

http://creativecommons.org/licenses/by/4.0/

(c) (i) Open Access

\begin{abstract}
We investigated the conformity of Japanese female students with varying self-esteem levels in a co-witness memory experimental paradigm. We had 24 Japanese female student pairs (18 - 26 years old) watch a video clip of a simulated criminal event together. Utilizing a presentation trick, we presented two different versions of the video clip simultaneously on the screen but allowed the viewers to observe only one without their being aware of the duality. Conformity responses were detected through analysis of the answer patterns showing change from their own to their partner's in pre- and post-memory tests. We also assessed self-esteem and divided the participants into three groups according to their levels. The results showed that participants with low levels of self-esteem tended to conform to their co-witness more often than those with high self-esteem scores. We found that personality traits would be crucial factors in conformity through the present study.
\end{abstract}

\section{Keywords}

Conformity, Self-Esteem, Japanese Female Students, Witness Memory Misinformation Paradigm

\section{Introduction}

When faced with different opinions presented to them directly by friends, partners, or others through any number of means such as mass media, the Internet or social networks, people may adopt the new ones as their own (conformity) or keep their original ones. Conformity is the behavioral tendency underlying various social phenomena, including fads in a variety of social settings, groupthink in decision-making, irrational behavior under panic, bullying in school, etc. What are the major factors underlying such conformity behavior? (See Bernheim, 1994 for a comprehensive review). 
The first attempt at experimentally investigating conformity in the laboratory setting was Asch (1956), who demonstrated that a participant under social pressure tended to conform to the majority even though their answer seemed obviously incorrect. The Asch experiments have been replicated with different parameters and with participants of different cultural backgrounds (See Bond \& Smith, 1996, for review).

One of the research areas in which conformity has been vigorously examined recently is in co-witness memory research (e.g., Gabbert, Memon, \& Allan, 2003; Garry, French, Kinzett, \& Mori, 2008). Often there is more than one witness at a crime scene or an accident. Might they testify differently to the police or in court even though they had witnessed the same event? Researchers in forensic psychology and applied cognitive psychology have been investigating the crucial factors of conformity among co-witnesses in experimental settings (See Jack, Zydervelt, \& Zajac, 2014, for a succinct review of recent findings).

Garry et al. (2008), utilizing a presentation "trick" (Mori, 2007), presented two different versions of a criminal event to co-witness pairs simultaneously, and then had the witnesses discuss what they had seen. Garry et al. found that participants often reported details they had adopted during the discussion in place of their own memory of the events. Gabbert et al. (2003) also presented different versions of an event to participant pairs such that one participant could see some details of the event that could not be seen by the other. They examined the participants' reports of the event and found that they "recalled" details not presented to them personally, but rather supplied by their partners who had actually observed them. Co-witness effects have been investigated rigorously by Garry’s colleagues (French, Garry, \& Mori, 2008; French, Garry, \& Mori, 2011; Hewitt, Kane, \& Garry, 2013) as well as by Gabbert's (Gabbert, Memon, \& Wright, 2006; Candel, Memon, \& Al-Harazi, 2007; Hope, Ost, Gabbert, Healey, \& Lenton, 2008; Paterson, Kemp, \& McIntyre, 2012).

However, these studies were somewhat limited by circumstantial factors, such as the interpersonal relationship between co-witnesses (intimate couples or not, French et al., 2008), or the number of co-witnesses (one-toone or one-to-two, Mori \& Mori, 2008). Hirokawa, Matsuno, Mori, and Ukita (2006) examined the personality traits of co-witness pairs along with the gender effect on conformity among co-witness pairs. They found that the masculinity levels of co-witnesses negatively correlated with conformity although there were no significant sex differences. The personality trait, masculinity, did matter, but not the actual biological sex. Therefore, it would be desirable to investigate the possible effects of other personality traits of witnesses on conformity in cowitness memory experiments.

The present study aimed to investigate the effects of personality traits of witnesses on conformity in co-witness memory experimental paradigms. In particular, we examined the effect of self-esteem of Japanese female students on their conformity in the co-witness memory experimental paradigm. We hypothesized that participants with low self-esteem would conform to their partners more frequently, while those with high self-esteem would stick to their own answers irrespective of those of others.

\section{Method}

\subsection{Participants}

Twenty-four Japanese female student pairs (18-to-26-year-olds; average 20.8 years old) participated as witnesses. All the participant pairs were volunteers from a women's university in Japan.

\subsection{Self-Esteem Questionnaire}

For the self-esteem assessment, we assembled a questionnaire with a set of 19 questions adopted from the selfesteem scale developed by Hiraishi (1990). These 19 items comprised three sub-categories of self-esteem: four items for measuring self-acceptance, seven items for self-actualization, and eight items for self-fulfillment. Selfacceptance was defined as acceptance of self despite deficiencies. It was assumed to include self-understanding and awareness of one's own competencies and deficiencies. Summed up, it was an individual's feeling that they were of "unique worth". Self-actualization is a term well-known for having been introduced by Maslow (1943) as the highest level of his famous pyramid called "Maslow's Hierarchy of Needs". The last of the three, selffulfillment, was defined as “carrying to fruition one's deepest desires or one’s worthiest capacities” (Gewirth, 1998).

\subsection{Simulated Witness Event and Memory Assessments}

The Takarangi Video Clips-The video clip used in the present study was originally made by Takarangi, Parker, 
and Garry (2006) and used in Garry et al. (2008). It depicted a simulated criminal event carried out by an electrician ("Eric") working in an unoccupied house, wherein he slipped away from his task and stole a number of items. The two versions of the movie were made to be identical except for eight critical items; for example, Eric tried on a black baseball cap in one version and a red cap in the other. The video ran for 6:34 minutes without audio.

Presentation of the Video Clips-We screened the video using a presentation trick, the MORI technique (Mori, 2007). This allowed the simultaneous presentation of two different versions of the clip on the same rear screen with each member of the participant pair able to observe only one version of the video without being aware of the other. The effect was achieved by having the participants wear polarizing sunglasses that permitted them to observe only one of the two videos on the screen.

Apparatus-We used two DLP projectors (TAXAN KG-PL011S). The rear screen was made of a 5 mm-thick pane of plain ground glass $(80 \mathrm{~cm} \times 80 \mathrm{~cm})$. The two types of sunglasses were prepared by mounting a pair of polarizing filters either vertically or horizontally into sunglass frames. The video presentation layout was outlined in Figure 1.

\subsection{Procedure}

Self-esteem questionnaire administration-Participants entered the psychology laboratory in pairs and completed the self-esteem questionnaire individually. It took about two to three minutes to answer the questionnaire.

Video presentation-The experimenter gave general instructions to the participants to watch the video on the screen and handed a pair of polarizing sunglasses to each participant, ostensibly worn to eliminate the glare of the rear projection. The two types of sunglasses were handed out at random. Then, the experimenter turned the room light off and presented the clip on the screen. After the presentation, the light was turned on again.

Before-discussion tests-Immediately after the video presentation, the experimenter handed out a memory test sheet with ten questions designed to assess participants' recollection. There were eight differing points in the Takarangi video, and we had chosen five of them for the memory test. They were the name of electrician written on his car ("RJ" or "AJ"), the bed in the house (made or unmade), the color of the cap the man wore (black or red), the picture on the wall (the Leaning Tower of Pisa or the Eiffel Tower), and the magazine the man read ("Time" or "Newsweek"). The other five questions were taken from the common items that had been shown to both of the viewers. The participants filled in their answers on the left half of the sheet, leaving the right half blank.

Collaborative recollection with discussion-In the collaborative recollection phase, the experimenter asked the participants to answer each question item aloud in turns. On each question, we allowed the pairs to discuss their answers when they did not match.

After-discussion tests-After the discussion, we used the same memory-test sheet as before the collaboration, on which the question items were printed side-by-side to correspond with each other, but with only the items on the left side already answered. This meant that the participants could see what they had answered before as they filled in the right side of the paper during the second test session. It took about five minutes to complete the test.

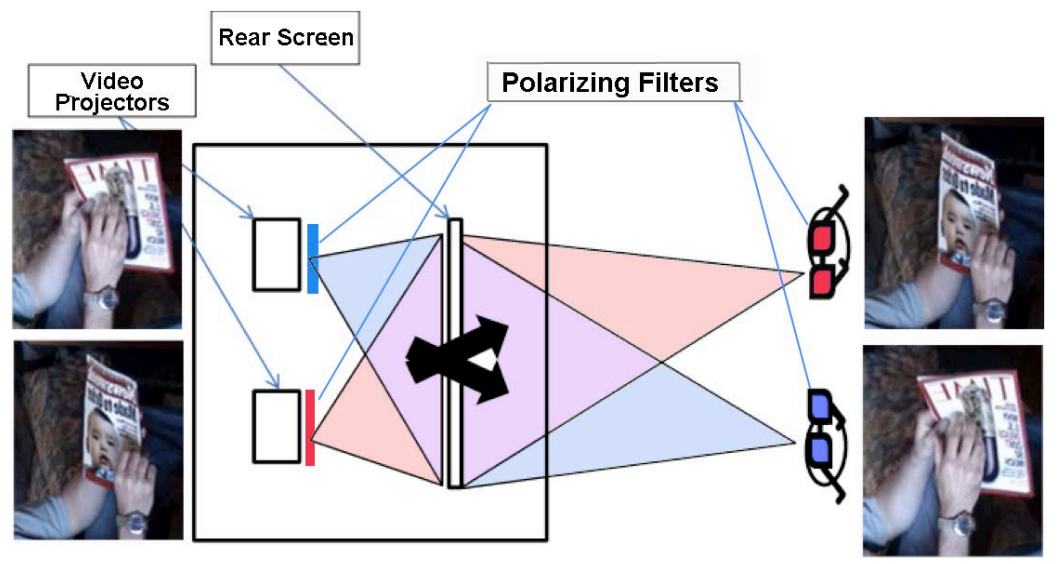

Figure 1. Diagram of experimental setting. 
Manipulation check and debriefing-At the end of the session, the experimenter asked the participants whether they had noticed any anomaly during the video presentation and then explained the experimental purposes and tricks to the participants.

\section{Results}

\subsection{Cluster Analysis Based on the Self-Esteem Scores}

We classified the participants utilizing a cluster analysis on their scores for the three sub-categories of the SelfEsteem Questionnaire. The cluster analysis divided the participants into three groups. The first cluster consisted of those participants with low Self-Efficacy scores throughout the three sub-categories. We named them the LE group, which had 11 students. The largest number of students was classified into the second cluster, characterized by high scores for both Self-Actualization and Self-Acceptance, but low scores for Self-Fulfillment. They were named the HE-LF group, for High-Self-Efficacy, but Low-Self-Fulfillment. There were 21 students in this group. And the remaining 16 students were classified into the HE group, High Self-Efficacy in general. The characteristics of the three groups are shown in Figure 2.

\subsection{Identification of Conformity in the Memory Tests}

According to the final manipulation check question, three participants answered that they noticed the duality of the video. However, none of them seemed have noticed the experimental purposes of the present study. Therefore, we included the data from those participants in the following analyses.

We classified the answer patterns in the two memory tests in the following way. For the before-discussion test, we devised three categories: writing an answer (A), writing "not remembered" (NR), or leaving a blank (B). For the after-discussion test, there were five categories: writing own answer (OA), partner's answer (PA), something else (E), "not remembered" (NR), or leaving a blank (B). Then, we defined "conformity" as the pattern in which the answer had been changed from A to PA, that is, after discussion it had been changed from "writing an answer" to "partner's answer."

\subsection{Conformity Frequencies of the Three Self-Esteem Groups}

Then we analyzed the relationships between the frequencies of conformity and the self-esteem groups. As shown in Figure 3, the LE group participants conformed almost three times more often than the other group participants. The differences were statistically significant $\left(F_{(2,45)}=8.355, p<.01\right.$; multiple comparison revealed at $5 \%$ significant level, LE > HE-LF, HE.) These results supported our hypotheses that low-esteem participants would conform to others, but high-esteem ones would not.

\subsection{Memory Modification Patterns and Sub-Categories of Self-Esteem}

We have analyzed further the relationships between the memory modification patterns and the sub-categories of self-esteem. We compared the frequencies of each memory modification pattern of the high versus low score

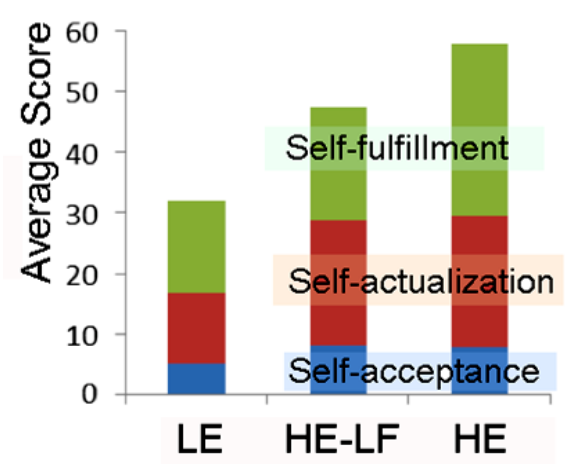

Figure 2. Characteristics of the three participant groups in terms of their self-esteem scores. 
groups of each sub-scale of self-esteem scores. Here, we only report briefly three findings that showed significant differences. First, the B-B patterns, i.e., participants responded with a blank at the first test and left a blank again at the second test after the collaboration, appeared significantly more often in participants with high Self-Acceptance scores than those with low Self-Acceptance scores (mean frequencies were .39 and .0, respectively; $\left.t_{(27)}=2.27, p<.05\right)$. Secondly, the A-OA patterns that showed the original answers were maintained after the discussion were more frequent in those participants with high Self-Actualization scores than those with low Self-Actualization scores (mean frequencies were 5.52 and 4.29 , respectively; $t_{(30)}=2.11, p<.05$ ). Lastly, a considerable number of participants with low Self-Actualization scores changed their answers to something else in the after-discussion test (the A-E pattern) while no participants with high Self-Actualization scores showed this answering pattern (mean frequencies were .38 and .0 , respectively; $t_{(20)}=2.17, p<.05$ ). These results meant that participants with low Self-Actualization scores tended to change their answers either to the partners' ones (conformity responses) or to something else after the discussion. We did not find any notable differences related to the participants' Self-Fulfillment scores.

\section{Discussion}

\subsection{Personality Traits and Conformity}

We hypothesized that participants with low self-esteem would conform to others more frequently than those with high self-esteem, and that the latter would maintain their answers steadfastly. To examine these hypotheses, we classified our participants into three groups; one Low Self-Esteem group, and two types of High Self-Esteem groups. In the latter two groups the only difference was their Self-Fulfillment scores. The co-witness memory performance revealed that the hypotheses were supported. Participants in the Low Self-Esteem group showed conforming patterns more frequently than the two High Self-Esteem groups. Through further analyses using sub-scales of self-esteem, we also found that High Self-Acceptance participants tended to maintain their answers even when they had made blank answers. On the contrary, participants with Low Self-Actualization scores tended to change their answers after the discussion. Meanwhile, Self-Fulfillment seemed to have little effect on memory modification. These results showed that personality traits are crucial factors in conformity. It would be desirable to examine other personality traits in co-witness memory experiments in the future.

\subsection{Limitations of the Present Research and Perspectives for Future Research}

There are limitations in interpreting the present results. The easiest variable to control in future studies would be the recall time. It would have been advisable to limit the recall time allowed. Also, in this study we could not control the intimacy levels of the participants. According to French et al. (2008), intimate couples showed more conformity behavior in their witness memory performance. The intimacy in the French et al. study was romantic. We would expect that intimacy in general or the lack of it, even between same-sex pairs as in the present study, might have an effect on memory modification. It was also one of the crucial limitations that only female students participated in the present study. As Hirokawa et al. (2006) found, there are certain gender effects. Our findings

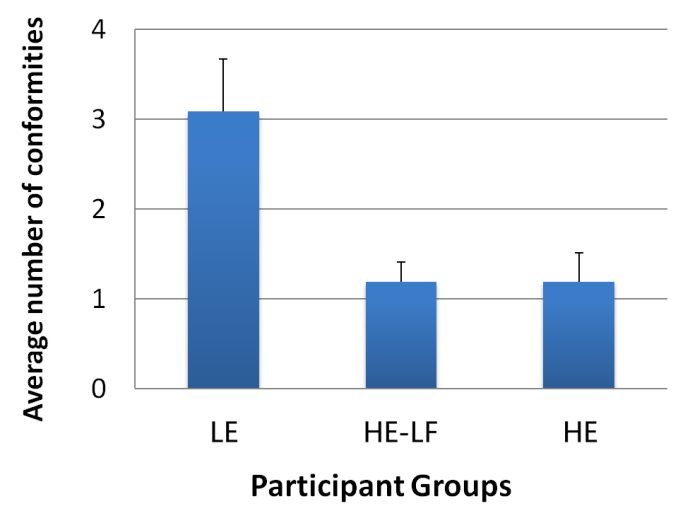

Figure 3. Average conformity scores for three groups (The error bars show the standard errors). 
were limited to female students; male participants would probably behave quite differently in relation to their self-esteem scores. Moreover, we might have had even more different answer patterns with mixed-sex pairs. It would also be interesting to examine the effect of self-esteem on memory modification in cultures other than Japanese.

\section{Conclusion}

Our hypothesis that participants with low self-esteem would conform to others more frequently than those with high self-esteem was experimentally supported. The results of the present study showed that personality traits are crucial factors in conformity. However, there are limitations in interpreting the present results. The present experiment failed to control major variables such as the recall time, the intimacy levels and the gender of the participants. It should be needed further studies to examine the personality traits other than self-esteem using cowitness memory experimental paradigms.

\section{Acknowledgements}

This research was supported by a Grant-in-Aid from the Japan Society for the Promotion of Science (KAKENHI Grant No. 25280050) to KM. The present paper is based on the capstone thesis of the first author conducted under supervision of the second author. We would like to express our thanks to the participants at Kyoto Notre Dame University. We are indebted to Rebecca Ann Marck for English editing.

\section{References}

Asch, S. E. (1956). Studies of Independence and Conformity: I. A Minority of One against a Unanimous Majority. Psychological Monograph: General and Applied, 70, Whole No. 416.

Bernheim, B. D. (1994). A Theory of Conformity. Journal of political Economy,102, 841-877. http://dx.doi.org/10.1086/261957

Bond, R., \& Smith, P. B. (1996). Culture and Conformity: A Meta-Analysis of Studies Using Asch’s (1952b, 1956) Line Judgment Task. Psychological Bulletin, 119, 111-137. http://dx.doi.org/10.1037/0033-2909.119.1.111

Candel, I., Memon, A., \& Al-Harazi, F. (2007). Peer Discussion Affects Children’s Memory Reports. Applied Cognitive Psychology, 21, 1191-1199. http://dx.doi.org/10.1002/acp.1355

French, L., Garry, M., \& Mori, K. (2008). You Say Tomato? Collaborative Remembering Leads to more False Memories for Intimate Couples than for Strangers. Memory, 16, 262-273. http://dx.doi.org/10.1080/09658210701801491

French, L., Garry, M., \& Mori, K. (2011). Relative—Not Absolute-Judgments of Credibility Affect Susceptibility to Misinformation Conveyed during Discussion. Acta Psychologica, 136, 119-128. http://dx.doi.org/10.1016/j.actpsy.2010.10.009

Gabbert, F., Memon, A., \& Allan, K. (2003). Memory Conformity: Can Eyewitnesses Influence Each Other's Memories for an Event? Applied Cognitive Psychology, 17, 533-543. http://dx.doi.org/10.1002/acp.885

Gabbert, F., Memon, A., \& Wright, D. B. (2006). Memory Conformity: Disentangling the Steps towards Influence during a Discussion. Psychonomic Bulletin and Review, 13, 480-485. http://dx.doi.org/10.3758/BF03193873

Garry, M., French, L., Kinzett, T., \& Mori, K. (2008). Eyewitness Memory Following Discussion: Using the MORI Technique with a Western Sample. Applied Cognitive Psychology, 22, 431-439. http://dx.doi.org/10.1002/acp.1376

Gewirth, A. (1998). Self-Fulfillment. Princeton, NJ: Princeton University Press.

Hewitt, L. Y., Kane, R., \& Garry, M. (2013). Speaking Order Predicts Memory Conformity after Accounting for Exposure to Misinformation. Psychonomic Bulletin and Review, 20, 558-565. http://dx.doi.org/10.3758/s13423-013-0377-4

Hiraishi, K. (1990). Seinenkiniokerujikoishiki no kozo: Jiko-kakuritu-kan to jiko-kakusan-kankaramitashinrigakutekikenko. [The Structure of Self-Consciousness in Adolescence: Psychological Health from a Point of View of "Self-Establishment" and “Self-Diffusion”]. Japanese Journal of Educational Psychology, 38, 320-329.

Hirokawa, K., Matsuno, E., Mori, K., \& Ukita, J. (2006). The Relationship between Masculinity-Femininity and Suggestibility in an Experimental Collaborative Eyewitness Testimony. Asian Journal of Social Psychology, 17, 533-543. http://dx.doi.org/10.1111/j.1467-839X.2006.00190.x

Hope, L., Ost, J., Gabbert, F., Healey, S., \& Lenton, E. (2008). “With a Little Help from my Friends...”: The Role of CoWitness Relationship in Susceptibility to Misinformation. Acta Psychologica, 127, 476-484. http://dx.doi.org/10.1016/j.actpsy.2007.08.010

Jack, F., Zydervelt, S., \& Zajac, R. (2014). Are Co-Witnesses Special? Comparing the Influence of Co-Witness and Inter- 
viewer Misinformation on Eyewitness Reports. Memory, 22, 243-255. http://dx.doi.org/10.1080/09658211.2013.778291

Maslow, A. H. (1943). A Theory of Human Motivation. Psychological Review, 50, 370-396. http://dx.doi.org/10.1037/h0054346

Mori, K. (2007). A Revised Method for Projecting Two Different Movies to Two Groups of Viewers without Their Noticing the Duality. Behavior Research Methods, 39, 574-578. http://dx.doi.org/10.3758/BF03193028

Mori, K., \& Mori, H. (2008). Conformity among Cowitnesses Sharing Same or Different Information about an Event in Experimental Collaborative Eyewitness Testimony. Perceptual and Motor Skills, 106, 275-290. http://dx.doi.org/10.2466/pms.106.1.275-290

Paterson, H. M., Kemp, R., \& McIntyre, S. (2012). Can a Witness Report Hearsay Evidence Unintentionally? The Effects of Discussion on Eyewitness Memory. Psychology, Crime and Law, 18, 505-527. http://dx.doi.org/10.1080/1068316X.2010.510117

Takarangi, M. K. T., Parker, S. L., \& Garry, M. (2006). Modernizing the Misinformation Effect: The Development of a New Stimulus Set. Applied Cognitive Psychology, 20, 583-590. http://dx.doi.org/10.1002/acp.1209 
Scientific Research Publishing (SCIRP) is one of the largest Open Access journal publishers. It is currently publishing more than 200 open access, online, peer-reviewed journals covering a wide range of academic disciplines. SCIRP serves the worldwide academic communities and contributes to the progress and application of science with its publication.

Other selected journals from SCIRP are listed as below. Submit your manuscript to us via either submit@scirp.org or Online Submission Portal.
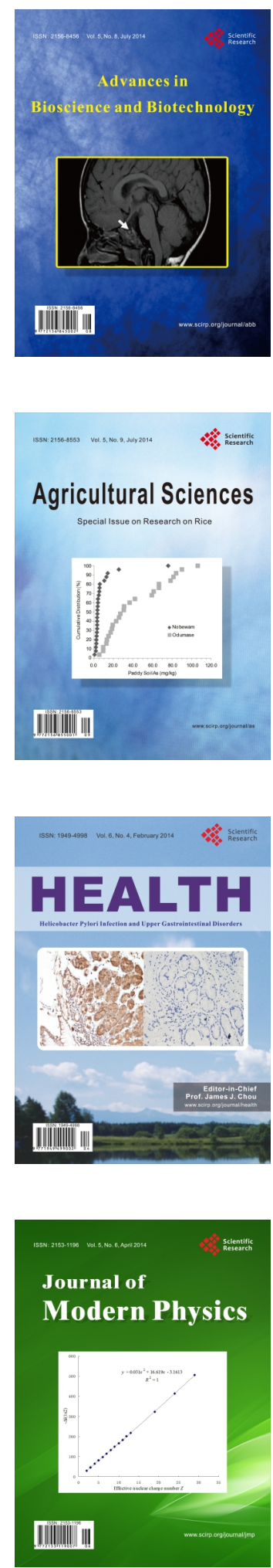
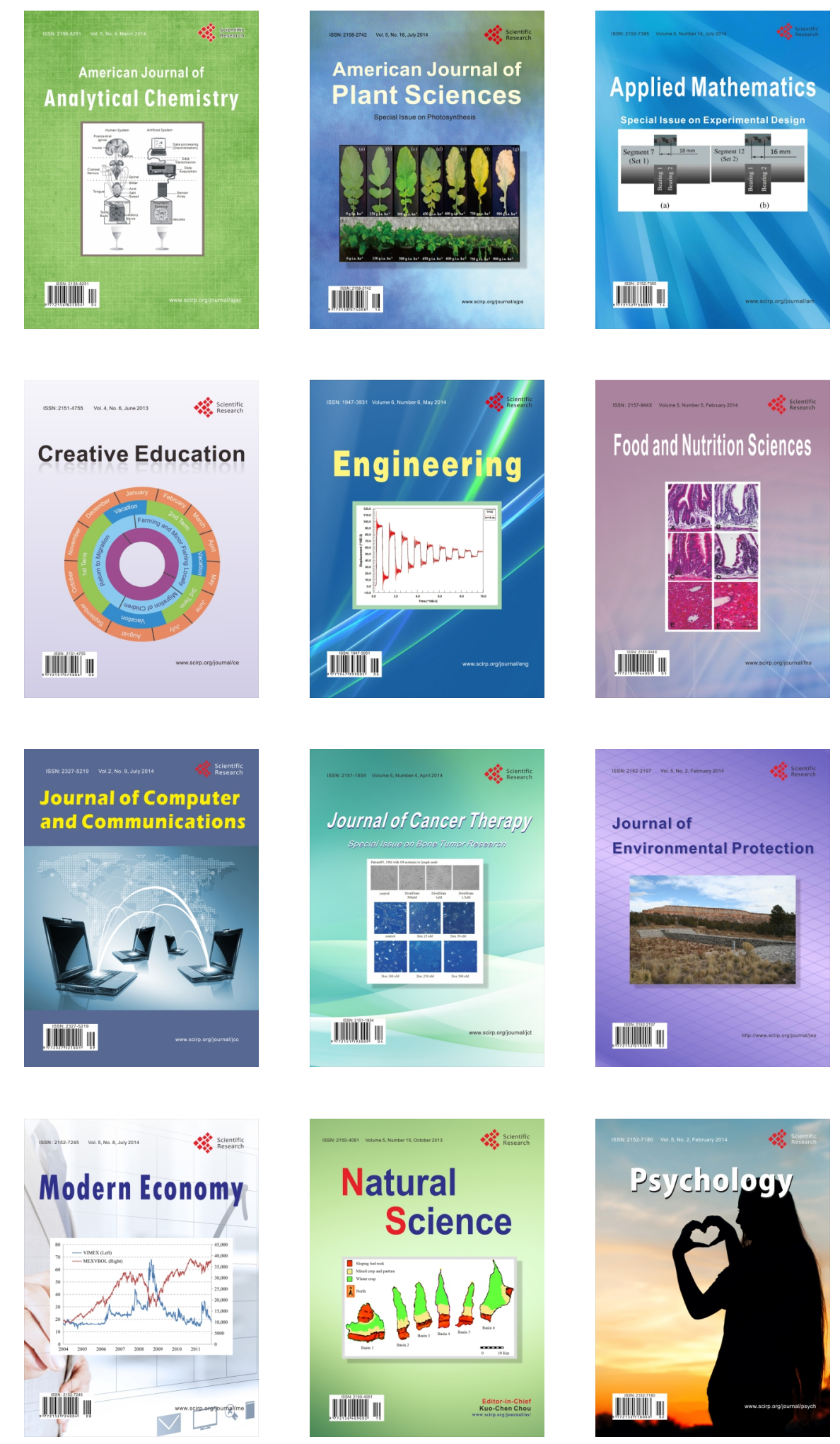